University of Nebraska - Lincoln

DigitalCommons@University of Nebraska - Lincoln

Faculty Publications: Department of Teaching, Department of Teaching, Learning and Teacher Learning and Teacher Education

Education

July 2004

\title{
The Roles of State Departments of Education as Policy Intermediaries: Two Cases
}

\author{
Edmund T. Hamann \\ University of Nebraska - Lincoln, ehamann2@unl.edu \\ Brett Lane \\ Brown University
}

Follow this and additional works at: https://digitalcommons.unl.edu/teachlearnfacpub

Part of the Teacher Education and Professional Development Commons

Hamann, Edmund T. and Lane, Brett, "The Roles of State Departments of Education as Policy Intermediaries: Two Cases" (2004). Faculty Publications: Department of Teaching, Learning and Teacher Education. 55.

https://digitalcommons.unl.edu/teachlearnfacpub/55

This Article is brought to you for free and open access by the Department of Teaching, Learning and Teacher Education at DigitalCommons@University of Nebraska - Lincoln. It has been accepted for inclusion in Faculty Publications: Department of Teaching, Learning and Teacher Education by an authorized administrator of DigitalCommons@University of Nebraska - Lincoln. 


\title{
The Roles of State Departments of Education as Policy Intermediaries: Two Cases
}

\author{
Edmund T. Hamann and Brett Lane \\ Brown University
}

\begin{abstract}
As the variety of state education agency (SEA) responses to the No Child Left Behind Act of 2001 demonstrates, different SEAs interpret the same federal educational policy differently. Nonetheless, little research has depicted how federal policies are changed by SEA-based policy intermediaries. Using an "ethnography of educational policy" approach, this article offers two illustrations of mediation processes at the SEA level: Maine's and Puerto Rico's initial attempts to implement the federal Comprehensive School Reform Demonstration program. Both attempts show that the mediation process is inevitable and that its general direction can be predicted: Policies will be adapted in ways that better correspond with local problem diagnoses, understandings, and habits of action. The study leaves intact McLaughlin's assertion that local negotiation and reframing of policy can be a source of improvement or added value. Such improvement is more likely if an expectation of mediation is explicitly accounted for and if what counts as improvement reflects local mores.
\end{abstract}

Keywords: SEAs, policy adaptation, Maine, Puerto Rico, CSRD

\section{State-Level Policy Adaptation: \\ A Context}

In a theoretically oriented piece, McLaughlin (1987) explained that policy implementation studies illustrate how the conversion of policy into practice is characterized by "bargaining and negotiation" and how policy as practiced dif- 
fers from policy as blueprint. A growing body of research empirically illustrates how state and federal educational policies are adapted, even coopted, when implemented in schools and classrooms (e.g., Coburn, 2001; Cuban, 1998; Datnow, Hubbard, \& Mehan, 2002; Hill, 2001; Irvine \& Larson, 2001; Sutton \& Levinson, 2001; Young, 1999). These works are important but suggest a question that to date has been little pursued: If policy is adapted by those in classrooms who are challenged with implementing it, might it also be adapted by those further removed from classrooms who are also charged with implementing it, albeit at a different tier? Spillane (1998) suggested that this is so at the district level. However, according to McLaughlin's understanding, it should be true at any tier at which policy must be understood to be enacted or passed along, including in state departments of education (also known as state education agencies [SEAs]). Recognizing that policy messages are continually interpreted within and across the multitiered educational system forefronts the key role of those at the interstices of the process of policy formation and implementation. The two cases reviewed in this article both illustrate examples of educators in SEAs adapting a federal policy - in each case the Comprehensive School Reform Demonstration (CSRD) program ${ }^{1}$ — as they mediated its implementation.

\section{Policy Intermediaries as Learners and Doers}

The growing body of literature on educational policy implementation argues that at whatever tier of the educational system one references, implementation is a process engaged in by context-embedded individuals that entails intertwined processes of interpretation, negotiation, sense making, bargaining, ambiguity management, and the exercise of discretion (Coburn, 2003; Elmore, 1980; Goggin, Bowman, Lester, \& O’Toole, 1990; Honig, 2001; McLaughlin, 1987; Spillane, 1998). From this perspective, individuals take action on the basis of their senses of what is, what can be, and what is supposed to be, thereby affecting the policy as implemented in practice.

Elmore's (1980) discussion of discretion draws attention to individuals as critical players in the implementation process. He argued that individual discretion combined with the bargaining that takes place among individuals and

The authors dedicate this article to the hardworking educators of the Maine and Puerto Rico departments of education, who routinely and effectively work to reconcile federal, state, and local educational policies. This article is based on work completed for The Education Alliance at Brown University and was supported by the Institute of Education Sciences (IES), U.S. Department of Education, under contracts ED-01-CO-0010 and RJ96005401. The opinions, findings, and conclusions or recommendations expressed in this material are those of the authors and do not necessarily reflect the views of the IES, the U.S. Department of Education, or any other agency of the U.S. government. 
organizations might be better understood "as a device for improving the reliability and effectiveness of policies at the street level" (p. 610), as those at the "street level" adapt policies in ways that match local sensibilities. Datnow et al. (2002) made a related point when they suggested that both educators and researchers need to better account for the inevitable "co-constructed nature of the implementation process" (p. 10). Drawing from them, we highlight that when faced with policy messages, individuals engage in constructivist processes. Their learning of new policies is affected by changing calculations of how much energy they want to expend to understand and enact them and what other concepts and plans they can or must link them to and reconcile them with. (See Rust and Freidus, 2001, for more examples of the applicability of constructivist learning theory to understand how educators respond to new programs and policies.) For each of these calculations (which may not be fully conscious), individuals consider personal consequences and consequences for policies if they act or not.

Yet the inevitable discretion of individuals does not mean that policy can be or is changed just any which way. An original policy, including its core elements of a problem diagnosis and a proposed response (Levinson \& Sutton, 2001), is the starting template on which subsequent acts of interpretation work. For that work, those interpreting or passing along policy explicitly and/or subconsciously reference other problem diagnoses and possible responses that they draw from organizational norms and institutional values embedded in their workplaces and from prior personal and professional experiences. This borrowing is constrained by the boundaries of interpreters' experiences and imaginations, as well as the emotional and moral shadings that Bakhtin (1993) and others (e.g., Hicks, 1999) have insisted are entwined in human cognition.

Proponents of bounded rationality theory (e.g., Leedom, 2001; Weick, 1995) offer a complementary perspective. Their emphases on the situated-ness of cognition and the idea that not all that can be known is known, and that not all that is known is found to be equally salient (with local social norms and habits affecting such valuing), leave intact the idea that a precipitating message (i.e., an original policy prompt) helps shape the context within which subsequent interpretation and action occur. Bounded rationality adherents argue that rational choice theory makes unreasonable assumptions about an individual actor's capacity and access to the "knowledge, time, attention, and other resources" in real-world settings (Gigerenzer \& Selton, 2001, p. 4). In bounded rationality, individual actors do make rational (with a small $r$ ) decisions, in that they try to figure out the preferred course of action in a given situation. But this decision-making process is better understood as a process of situational awareness whereby individuals use heuristics and previous experiences to adapt and 
respond to situations. Aware, consciously and subconsciously, of rules, traditions, habits of interaction, problem diagnoses, and intentions, they do "what makes sense."

\section{Looking at SEAs}

Although it is known that policies are necessarily refined, adapted, supplemented, and perhaps co-opted or even sabotaged (Levinson \& Sutton, 2001) along the policy-to-practice continuum, there is a lack of much description of mediating and adapting processes. In particular, there is a limited record considering the in situ roles and understandings of administrators of SEAs as they act as intermediaries of federal policy. The first purpose of this article is to start filling this research gap.

Second and third, SEAs should be studied because they are powerful and paradoxical; they control substantial resources, regulate schools' adherence to laws, and are dominant within the hierarchy of K-12 education; hence, paying explicit attention to them allows for the examination of policy as the practice of power that Levinson and Sutton (2001, p. 1) highlighted. But SEAs "have little control and no proximity" to the sites they are trying to change (Lusi, 1997, p. 11). Actually, "modest proximity" might be a useful way of qualifying Lusi's (1997) assertion when comparing those in SEAs with those in the U.S. Department of Education or other federal policy-making bodies. Although SEA personnel's practice of power depends on others' subsequent interpretations and actions, those in SEAs often come from and interact with local school and district contexts. Because of their familiarity with local cultural mores and reform histories, SEA-based personnel are positioned to adapt policy messages to improve local intelligibility and persuasiveness.

That prospect, however, does not promise that user-friendly adaptation will occur at the SEA level or that the crux of the original message will automatically be protected. A fourth reason for studying SEAs is that they have traditionally been loci of policy creation. Thus, an increased federal role in education may well be viewed by SEA personnel as a challenge to their self-assumed authority and to organizational norms.

Fifth, looking at SEAs positions us to challenge the policy maker-policy implementer dualism that is common even in the newest scholarship (e.g., Spillane, Reiser, \& Reimer, 2002). SEA personnel in relation to federal policy do not easily fit on only one side or the other of this division, because in passing along policy as implementers, they reshape it. Sixth, SEAs are highly exposed to state and national politics, and that exposure to politics seems salient to any policy flowing through SEAs that claims to be "research based" or "scientifically based," as educational policies seem increasingly to be asked to 
be (Whitehurst, 2003). Whatever the research base that might obtain in clinical conditions and that might underlie the logic of policy initiators, policy that flows through SEAs and that is reconciled with other policies and priorities will necessarily not be so sanitized, though neither McLaughlin (1987) nor the ethnographically derived case studies that follow frame this slippage from the clinical as intrinsically problematic.

Finally, the federal No Child Left Behind Act positions SEAs as intermediaries with more discretion than in previous elementary and secondary education acts (ESEAs). As Section 7305a reads,

The purpose of this subpart is to allow States and local educational agencies the flexibility - (1) to target Federal funds to Federal programs that most effectively address the unique needs of States and localities; and (2) to transfer Federal funds allocated to other activities to allocations for activities authorized under subchapter I of this chapter.

Desimone (2002, p. 436) noted that the CSRD program gave states "a great deal of latitude" for implementation, requiring only the coherent integration of nine principle-like components. Thus, a look at SEAs' implementation of the CSRD program might provide insight into how SEAs will mediate the newer but much more substantial implementation of the No Child Left Behind Act.

\section{Why CSRD}

If there are multiple reasons to examine SEAs, this is also a propitious time to look at the comprehensive school reform movement. Currently, that movement is simultaneously becoming larger and more sharply questioned (Berends, Kirby, Naftel, \& McKelvey, 2001; Desimone, 2002; Lytle, 2002; Sack, 2002; Viadero, 2001). As of this writing, the long-term prospects of the CSRD program are uncertain.

With the Obey-Porter legislation that launched the CSRD program now more than half a decade old, there is a quickly growing number of studies and reports on comprehensive school reform generally that tell the history of the program's creation (e.g., Borman, Hewes, Overman, \& Brow, 2003; Coady et al., 2003; Desimone, 2002; Murphy \& Datnow, 2003). Repeating only a few key facets of that history to position readers to see later how the two cases reviewed here depart from and/or flesh out the federal template, it is important to note that the CSRD program represents the convergence of three powerful ideas: (a) that the federal government should use its investment in public education to promote equity (i.e., to target resources at schools that enroll large percentages of low-income students); (b) that whole-school reform strategies encompassing all students and staff members are superior to non- 
aligned aggregations of different programs targeting different students; and (c) that research-based, externally developed "models" can be key catalysts for improvement.

The first of these ideas dates back at least to the first ESEA of 1965. In turn, the 1988 and 1994 ESEA reauthorizations can both be characterized as reconciliations of the second idea with the first, particularly because the Improving America's Schools Act of 1994 led to the increasingly common redesignation of schools serving large numbers of low-income students as "Title I Schoolwide" (Anstrom, 1995, p. 3). At such schools, Title I funds are intended to improve the school experiences of all students (not just Title I-eligible ones). Such schools are also required to draft comprehensive plans for how their Title I and other resources will foment whole-school change.

The origins of the third idea - that of bringing in external models - can be trace back at least to the creation of the Coalition of Essential Schools in the mid-1980s and perhaps farther back, but it was the New American Schools initiative of the first Bush administration that substantially advanced and popularized this idea. That initiative paid for the full-fledged development and scaleup of seven whole-school reform models-Authentic Teaching, Learning, and Assessment for All Students; Audrey Cohen College; Co-nect Schools; Expeditionary Learning Outward Bound; Modern Red School-House; America's Choice; and Roots \& Wings - each of which shared "a unifying design that allows all staff members to perform to the best of their abilities and that integrates research-based practices into a coherent and mutually reinforcing set of effective approaches to teaching and learning for the entire school" (Berends, Bodilly, \& Kirby, 2002, p. 168).

The CSRD program authorized in 1997 and begun in 1998 was the first large-scale combination of these three ideas. The new program was announced just after authors from John Hopkins University and Abt Associates released the final report of a federally funded study of the education of "disadvantaged children." The fourth recommendation of the report argued,

\footnotetext{
Within the schools observed during first through third grades, students in schools using externally developed designs tended to achieve greater academic gains than did students in locally developed programs. Students in schools working with whole school reform tended to achieve greater gains that did students in schools attempting various pull-out programs. (Stringfield, Millsap, \& Herman, 1997, p. 1)
}

Although this was hardly the only impetus for combining the three ideas, and though it made a claim only at the elementary level, as the CSRD program was launched, both the formal program guidance and informal communica- 
tion from the U.S. Department of Education included the expectation that it would primarily assist schools serving low-income enrollments to import externally created whole-school reform models. In 1998, the federal government allocated \$145 million to the CSRD program (a sum that in subsequent years was more than doubled), of which $\$ 595,329$ was directed to Maine and $\$ 4,405,477$ to Puerto Rico (U.S. Department of Education, Office of Elementary and Secondary Education, 1998). In their first rounds of CSRD grants, Maine supported 11 high schools and Puerto Rico supported 75 schools of varying grade levels.

\section{Method:}

The Ethnography of Educational Policy

Young (1999) noted that traditional policy studies can effectively examine the intended outputs of policies and the fidelity of implementation, but they provide less illumination regarding how policy reshapes contexts, affects individuals' self-concepts and capacities to act, and legitimates certain norms of behavior. Ozga (1999) argued that educational policy is neither a neutral product nor one produced exclusively at one tier without negotiation at others. She then argued that educational policy research needs to factor in both the contributory roles and interested perspectives enacted by those all along the policyto-practice continuum. Traditional policy studies are not designed to answer well questions such as "How and when is a policy, such as the CSRD program, changed as it becomes practice?" or "What makes the CSRD program salient to an SEA employee?"

A central purpose of ethnography is to study the in-context sense making engaged in by individuals as parts of groups. Each educator and administrator along the policy-to-practice continuum must pose the question, "What are my colleagues and I being asked to do?" Each person's answers and consequent actions depend not just on interpretations of a specific policy but also on reconciliation of the new policy with other policies, with personal experiences, and with institutional norms and value judgments about what needs to be done (Spillane et al., 2002). Adaptation is inevitable (Levinson \& Sutton, 2001; McLaughlin, 1987, Shore \& Wright, 1997).

Proponents of the nascent field of ethnography of educational policy (e.g., Hamann, 2003; Levinson \& Sutton, 2001) note that this subfield is new. So, by necessity, it borrows from other research genres. In this article, not only are related theories of learning incorporated (e.g., constructivism, situated cognition, bounded rationality) and an interdisciplinary field-policy implementation studies - heavily borrowed from, but also, the boundaries between traditional 
ethnography and case study are blurred. Like other ethnographies, a premise here is that culture matters, is identifiable, is socially produced, is enduring but not static, and references partially shared webs of meaning (McQuillan, 1998).

The research methods we pursued included the traditional source of ethnographic knowledge - participant observation - reconciled with other forms of data collection. We pursued Nader's (1972) injunction, updated recently by Eisenhart (2001), that data collection strategies should be multiple and as eclectic as necessary, with the question to be answered determining methodological particulars. This approach is also consistent with recommended methods for case study data collection (Cresswell, 1998).

Cresswell (1998) argued that a defining element of a case study is its boundedness. This characteristic is true of both cases that follow, because they referenced a particular program (CSRD), a finite time period (the initial rollout of the CSRD program), and discrete entities (two SEAs). Consistent with Stake's (1995) description of an instrumental case study, both of our cases were selected for the ways they could illustrate an issue: the adaptation of educational policy at the SEA level. Our sampling was both expedient and purposeful; expedient because, by contract, we and our colleagues at the Northeast and Islands Regional Educational Laboratory have conducted applied research and technical assistance related to the CSRD program in seven states plus Puerto Rico. Maine and Puerto Rico were among a relatively small number of cases we knew well and for which we had ready access to a wealth of data. But our sample was also purposeful; in looking at our eight potential cases, we realized that both Maine and Puerto Rico stood out as examples of exaggerated policy adaptation (i.e., the substantial adaptation of an original policy), though examples of adaptation could be found in all eight. Also, our niche as applied CSRD researchers at an organization with a federal contract to support CSRD implementation meant that we had routine access to the federal CSRD guidance that was being shared with the SEAs.

We also picked Maine and Puerto Rico for reasons beyond the illustrative potential of each case. Comparing these two jurisdictions in terms of culture, language, climate, local educational norms, and historical relations with the U.S. Department of the Education shows how dissimilar Maine and Puerto Rico are. Thus, juxtaposing Maine and Puerto Rico matched the logic of what Patton (1990) called "maximum variation sampling" (p. 172). If commonalities emerge from the analysis of explicitly different cases, then such commonalities likely pertain elsewhere. (See also Eisenhart \& Howe, 1992).

The data collection strategies used for both cases included participant observation, reviews of policy documents, and informal and semistructured interviews. These were also the primary information sources grounding our un- 
derstanding of the CSRD template created at the federal level. However, these methodologies were not pursued to equal degrees.

Most of our data from Maine came from field notes collected as part of 4 years of technical assistance and applied research. These data included more than 70 days of accompanying Maine SEA personnel as they carried out "midcourse review" visits to CSRD high schools across the state. The data included notes from seven professional development institutes at which SEA officials convened grant-receiving high schools. They included notes from observing more than 60 end-of-year portfolio presentations by CSRD grant recipients to SEA personnel. Complementing this participant observation, we also reviewed achievement test data, the Maine Department of Education's (MEDOE) requests for proposals (RFPs) disseminated to potential CSRD applicants, and multiple approved Rider A agreements (described further in the case).

In contrast, though Puerto Rico Department of Education (PRDOE) officials were accompanied on 10 days of site visits to CSRD schools in 2000, and notes were also taken during our participation in three workshops on CSRD evaluation convened by the PRDOE also in 2000, the bulk of that case's data came from 400 pages of policy documents and notes generated in 1998 by PRDOE-based educators and three of our colleagues as they used federal CSRD monies directed to our employer to support the PRDOE's initial CSRD implementation.

Our understanding of the federal CSRD template came from document reviews and participation in several Title I and CSRD-focused, U.S. Department of Education-organized events, including three events at which we copresented with SEA personnel from Maine and one that was attended by SEA personnel from Puerto Rico. We also participated on committees and in events of the National Clearinghouse on Comprehensive School Reform, a federally funded organization begun at the same time as the CSRD program and charged with providing information and resources supporting whole-school reform implementation.

Although this is the first time we have juxtaposed the Maine and Puerto Rico cases, we previously analyzed most of the data used for the cases that follow for formative evaluations and peer-reviewed articles (Hamann \& Lane, 2002; Hamann, Lane, \& Hudak, 2001; Hamann, Lane, \& Johnson, 2001; Hamann, Lane, Smith, \& Piñeiro, 2001; Lane \& Hamann 2000, 2001, 2002a, $2002 \mathrm{~b}$ ). Because of our multiple uses of portions of the two data sets, our analysis has been necessarily recursive.

Our hypothesis, that policy interpretations must occur in SEAs, emerged slowly as a product of our planning for and reflections on interactions with SEA personnel, as well as our review of pertinent literature. So, for our case analysis, we looked for confirming and disconfirming evidence of our hypoth- 
esis. Much of this was not difficult, because some of our evidence, such as Maine's request for a waiver from some federal CSRD requirements, was obvious and overt. After examining our data sets to develop chronologies of implementation, we compared each case to the federal CSRD implementation template we had derived from early federal guidance. We looked closely for responses to federal guidance and examples of reconciliation of CSRD with other policies because such examples would be particularly apt for illustrating processes of SEA-level policy adaptation.

The federal creators of the CSRD program intended SEA-level interpretation, but they also offered enough regulatory and nonregulatory guidance to outline a reasonably detailed program template. Thus, comparing Maine's and Puerto Rico's implementations with the federal template illustrates exaggerated adaptation, but readers should not understand our illustration of that adaptation to imply anything untoward or inappropriate on the part of those we studied and worked with. Yes, they were policy intermediaries who shaped how the CSRD program was subsequently implemented in their jurisdictions, but they were supposed to be.

\section{The Case of Maine}

For the purposes of comparability, both the Maine case discussed below and the Puerto Rico case discussed in the next section are organized similarly. Both start with a context section that has two elements, a brief overview of salient cultural and long-term historical factors and then a more targeted focus on newer historical events relevant to how CSRD implementation proceeded. This positions readers to subsequently see how state-level CSRD adaptation proceeded in locally responsive directions. The second portion of both cases depicts the interpretations of policy engaged in by SEA officials and those advising them, positioning readers to see how CSRD policy within Maine and Puerto Rico diverged from the original federal template.

\section{Excellence and Skepticism: The Maine Context}

Historically, Maine has prioritized schooling, which is evidenced by the state's current and historically high levels of literacy and its status as third highest nationally in investment in education as a percentage of gross state product. In 1997, Maine trailed only Vermont and West Virginia in education spending per \$1,000 of gross state product ("Quality Counts 2000," 2000).

Historically, too, Maine's citizens and educators alike have been deeply skeptical of anything "top down" (Ruff, Smith, \& Miller, 2000). Perhaps this explains Maine's intriguing response to the recent interrelated national move- 
ments for high standards and accountability. Like most states, Maine has crafted a detailed list of content and performance standards - the Maine Learning Results - that all students are expected to master before graduating. But unlike many states (e.g., Texas and Massachusetts), which have created high-stakes tests to ascertain students' mastery of those standards, Maine has instead created a "low-stakes" test - the Maine Education Assessment (MEA) test — and then determined that the MEA cannot count for more than $10 \%$ in determining whether a student has mastered standards. Instead, each school district has been charged with developing local common assessments (LCAs). Per Maine's proud heritage of strong schooling, LCAs are to be rigorous. But in accordance with a preference for local control, the determination of how students' achievement of rigorous standards is to be demonstrated and measured is considered a local concern, with the state's input limited to approval. That said, the requirement to draft LCAs and the very Maine Learning Results themselves have, in many circles in Maine, been understood and resented as examples of state intrusiveness. This matters to our case because it helps explain why SEA personnel at the time the CSRD program was initiated in Maine wanted to avoid the appearance of mandates.

In Maine, there is a local disposition for educational decision making to be participatory, with a presumption that external expertise (i.e., from beyond Maine) requires internal mediation, adaptation, and adjustment. The creation of Promising Futures (Maine Commission on Secondary Education, 1998), a framework for high school reform that figures substantively in Maine's CSRD implementation story, is a good recent example of this preference for the inclusive, within-state development of educational policy.

Developed by the ad hoc Maine Commission on Secondary Education (1998), Promising Futures is a high school reform blueprint that outlines ways Maine could counter the problem of decreasing success among its secondary students. The commission was composed entirely of Maine educators (teachers, principals, superintendents, SEA officials, and higher education faculty members), ${ }^{2}$ with direct external input coming only from Ted and Nancy Sizer and from several of our colleagues at Brown University. ${ }^{3}$ This internal emphasis should not be misunderstood as isolationist skepticism. Indeed, many of the members had been trained outside of Maine and participated in professional networks such as Foxfire, the Coalition of Essential Schools, and the Northeast Secondary Network that were dominated by non-Mainers. Rather, the internal emphasis is better understood as reflecting the commission creators' awareness that a Maine-produced policy document would have greater within-state currency than something perceived as imported. At the beginning of Promising Futures, the commissioner wrote, 
The report of the Commission on Secondary Education represents a critical milestone in Maine education; for the first time in the State's history, a group consisting of some of our [italics added] finest educators has undertaken a comprehensive review and analysis of the condition of our system of secondary education. (p. iii)

Promising Futures (Maine Commission on Secondary Education, 1998) reconciles the multiple problem diagnoses and strategies of the commission members (including the input they solicited) and that of Maine's commissioner of education. According to the commissioner's problem diagnosisthat Maine fourth graders dramatically outscored their peers from other states on the National Assessment of Educational Progress, that Maine eighth graders somewhat outscored their peers nationwide, but that Maine high school students were indistinguishable from the national average-Maine needed to prioritize its school improvement efforts at the high school level. The commission responded by articulating 6 core principles, 15 core practices, and a three-page list of typical high school activities that should be discontinued. In a very real sense, the authors of Promising Futures crafted a process model for wholeschool change like many supported in the federal CSRD legislation. However, Promising Futures was not initially labeled as a school reform model, and unlike other models, it does not have a nongovernmental model development and support infrastructure.

Although released with substantial fanfare, Promising Futures (Maine Commission on Secondary Education, 1998) was carefully launched as a framework with which schools could voluntarily engage (i.e., not a mandate). Moreover, its implementation was largely unfunded, though the commissioner made funds available to create a new entity to support Promising Futures within the MEDOE — called the Center for Inquiry in Secondary Education (CISE) - that he quickly staffed with veterans of the Maine Commission on Secondary Education. He also committed funds to partially support some Promising Futuresthemed summer workshops.

\section{Adapting the CSRD Program to Support High School Reform}

For Maine, as for several small states nearby (e.g., New Hampshire and Vermont), there were preliminary reasons to be skeptical of the CSRD program when it was first being promoted in 1998. Given that the CSRD program had certain fixed costs for SEAs (e.g., drafting an implementation plan for the U.S. Department of Education, drafting RFPs for schools, and soliciting and then reviewing schools' applications), the modest amount of available funds for the MEDOE (less than \$30,000) and for schools was not necessarily worth the effort. ${ }^{4}$ Yet Maine embraced the CSRD program after making two 
key adaptations to federal policy: restricting its grant awards to high schools and attaching its award process to the Promising Futures (Maine Commission on Secondary Education, 1998) initiative. The department then appointed the CISE rather than the Title I office to oversee implementation and hired key personnel, who both reconciled the CSRD program with the state's Rider A policy and cultivated personalized, trusting relationships with school-based implementers that made CISE personnel facilitators in the school-level implementation process. This also set up the culturally welcome prospect of the lateral exchange of procedural knowledge, whereby practitioners at different schools helped one another with implementation.

The initially cautious stance toward the CSRD program within the MEDOE changed when one of the members of the ad hoc Maine Commission on Secondary Education (1998) convinced a deputy commissioner that the CSRD program and Promising Futures could be linked. With input from the commission veterans, senior MEDOE administrators successfully requested federal waivers to restrict Maine's CSRD competition to high schools, to attach parts of Promising Futures to the RFPs distributed to schools, and to skip favoring Title I improvement schools in its awarding (though Maine awarded needbased points in its grant scoring process).

Once the waivers were granted, the CSRD program was no longer just a small new federal program with a lot of procedural details; instead, it was a means to realize a locally articulated high school reform agenda around which there had been much recent mobilization. Attaching CSRD money to the promotion of Promising Futures (Maine Commission on Secondary Education, 1998) also circumvented the possible hazards of a mandate-oriented Promising Futures implementation strategy. Instead, Maine could encourage it with a "carrot" for schools of $\$ 50,000$ per year for 3 years.

With the CSRD program in Maine formally linked to Promising Futures (Maine Commission on Secondary Education, 1998), it was easily argued (within the MEDOE) that the newly created CISE should coordinate its implementation. This further strengthened the link between the CSRD program and Promising Futures, because the CISE employed several former high school educators who had served on the commission that had drafted Promising Futures. The link to the CISE meant that these SEA-based educators could contribute as a team to the coordination of CSRD implementation, even if only one CISE staff member was formally designated as the CSRD coordinator. As a CISE-based educator observed to us in May 2002, "If we had to revert to relying on the 5\% [SEA-level CSRD] allocation, we'd only be doing compliance and checklist activities, no leading." Instead, the state's investment in the CISE meant that the CSRD program was coordinated by a team, with the ratio of SEA staff members to implementing schools as low as 1:4. 
With modest CSRD monies arriving in 1998, the CISE quickly hired an 8year veteran social studies teacher to officially head CSRD implementation. Although she had not served on the commission that drafted Promising Futures (Maine Commission on Secondary Education, 1998), this teacher had worked at a school that was an important template for that framework's design and recommendations, because the principal for whom she had worked had been the commission's co-chair. Thus, the experiential lens that Maine's first (and so far only) CSRD coordinator brought to her task came from working at an innovative high school that had seen its test scores improve in the 1990s concurrent with the principal expecting teachers to develop curricula, to create common assessments, to evaluate student portfolios, and to otherwise actively develop the collective professional competence of the school. Teacher voice, teacher collaboration, distributed leadership, reflective experimentation, and peer-to-peer accountability were each core elements of this school's ethos. ${ }^{6}$

Although we think that the most important influence of the Maine CSRD coordinator's prior teaching experience was on the operating philosophy by which she pursued overseeing CSRD implementation, there were several more tangible manifestations. Two examples follow. First, as part of the CSRD RFPs to which schools responded and then as part of how they were to implement Promising Futures (Maine Commission on Secondary Education, 1998) and the CSRD program, the coordinator instructed schools to name leadership teams to oversee implementation. Schools responded by creating teams of teachers, administrators, and occasionally students and parents for this task. At the school level, the CSRD program was not to be managed by a traditional administrative hierarchy but instead through the professional collaboration of differently situated education stakeholders.

Second, as the most comprehensive mechanism for schools to demonstrate the extent of their grant implementation, since Maine's 1st year of the CSRD program, the coordinator has had schools maintain detailed portfolios chronicling their grant implementation. Organized along guidelines crafted by the CSRD coordinator (in collaboration with her CISE colleagues and with reference to federal implementation expectations), at the end of each academic year, schools presented their portfolios to CISE staff members (and, since 2003, to other schools). Technically, this exercise was an occasion for the approval or disapproval of implementation on the part of the CISE, but more substantively, the portfolio crafting, presentation, and review were vehicles for celebrating successes, instilling habits of data collection and review, identifying and troubleshooting challenges, and modeling the relationships of familiarity and support that have characterized CISE-school interactions with regard to the CSRD program. The idea of portfolio assessment, which the CSRD coordinator had 
previously used in her classroom, became an important and official mechanism of accountability and school-CISE communication (Hamann, Lane, \& Johnson, 2001).

Promising Futures (Maine Commission on Secondary Education, 1998) was not the only state-produced policy tool pertinent to Maine's adaptation of the CSRD program. Pursuant to state law requiring a highly detailed annual Rider A contract for allocations of more than $\$ 25,000$, each CSRD school each year has had to complete a Rider A, a document that doubles as a work plan and a grant proposal update. The already referenced school portfolios were then used as evidence of Rider A compliance. The Rider A issue shows how a new federal policy - the CSRD program - made an existing state policy salient in a new way.

Given the assertion that Maine educators are skeptical of top-down mandates, readers may wonder why the Rider A and school portfolio requirements did not spawn substantial resistance. The habits of action engaged in by Maine's CSRD coordinator and her CISE colleagues and the way they positioned themselves in relation to state and federal "requirements" were key elements of CSRD praxis in Maine. The preexisting Rider A requirement allowed the coordinator and other CISE staff members to position themselves sympathetically with school staff members. Instead of being the "heavies" demanding compliance with Promising Futures (Maine Commission on Secondary Education, 1998), they were able to represent themselves as advocates and assistants who could help with a burdensome bureaucratic procedure (i.e., Rider A) that they could not change. ${ }^{7}$

More generally, the SEA staff members overseeing CSRD implementation combined a personable, interactive style with deliberate attempts to build and share their expertise regarding high school improvement. This reduced potential skepticism regarding their motives and presumptions. During site visits, retreats, portfolio presentations, and other venues of SEA-school interaction, SEA staff members shared tales from other CSRD schools and from their previous practice as high school teachers and administrators. At these same interactions, SEA staff members also listened and learned, meaning that the repertoire of stories, circumstances, and strategies that they could later share only grew.

Maine's departure from the federal blueprint by linking the CSRD program, Promising Futures (Maine Commission on Secondary Education, 1998), and the CISE created an exploitable similarity between all of Maine's CSRD schools and an impetus for the lateral exchange of information regarding best practices. There were two common routes for this lateral exchange between Maine CSRD schools: exchange through intermediaries such as CISE staff members and direct exchange between educators from different schools, either 
at regional professional development activities or through direct visits to one another's schools. CISE staff members created formal and de facto policies that enabled both. Formally, they arranged several meetings for CSRD schools over the course of the year (including summer academies), scheduled daylong visits to CSRD schools, and gathered detailed written renderings (i.e., portfolios) about implementing schools' experiences. These policies permitted CISE staff members to learn much about the particular struggles and successes of given schools and to use such learning to enhance their procedural knowledge about high school improvement that they could subsequently share. In turn, the convening and multiple tales during site visits of the experiences of other implementing schools created a kind of community among the cohort of CSRD schools, community that was reinforced through direct visitation by staff members from one CSRD school to another.

\section{The Case of Puerto Rico}

The case of Puerto Rico's CSRD implementation focuses on a much shorter time period (mostly just 1998) than the Maine case, but it too illustrates how SEA staff members reconciled local educational norms, expectations, and social realities with the initial federal CSRD template. Three of our colleagues worked closely with PRDOE staff members during the first half of 1998. Much of what follows is based on their documentation of that 6-month time period or on information we gathered during two CSRD support visits we conducted in 2000 .

\section{Island and the Mainland, Island Versus the Mainland}

Given the history of colonialist intervention in Puerto Rico's educational system (Nieto, 2000), educators there may have had even more of a reason to be skeptical of federal educational initiatives than their counterparts in Maine, but there were two factors, neither extant in Maine, that would reduce overtly displayed skepticism of federal policy. First, until centrally mandated 1993 legal changes requiring the increased site-based management of schools, public education on the island had been organized in a particularly hierarchical, topdown manner. Second, Puerto Rican schools have long been disproportionately dependent on federal support (Resnick, 1993): In 1998-1999, 27.7\% of K-12 education spending in Puerto Rico was federal, almost 4 times more than the national average of $7.1 \%$ (Johnson, 2001). This greater federal dependence may have stimulated an impulse to "bite the hand that feeds," but our data suggested that the adaptation rather than the rejection of federal imperatives was a more typical response. 
Puerto Rico's response to the CSRD program is related to its educational history. Prior to the 1990s, one needs to look back to the 1940s to find major changes in Puerto Rican K-12 schooling policy. However, in the last decade of the 20th century, substantial reform laws were passed three times: in 1990, 1993, and 1999. The 1993 reform (based on La Ley Orgánico 18 del 1993) required the decentralization of school administration. Almost immediately thereafter, the 1994 ESEA, the Improving America's Schools Act, meant that many of Puerto Rico's schools were eligible to become Title I Schoolwide schools. Because of the requirement that Title I Schoolwide schools draft improvement plans, just as Puerto Rico's principals were gaining site-based management responsibilities, they were also asked to organize and be responsible for whole-school reform.

In response to the federal shift in emphasis (Anstrom, 1995), many of Puerto Rico's schools rapidly relabeled themselves as "Schoolwide" and drafted the requisite school improvement plans. In 1996, 362 of Puerto Rico's approximately 1,500 public schools were formally Title I Schoolwide; by 1999, the number had grown to 685; and by 2001, Puerto Rico had 1,393 Title I Schoolwide schools enrolling $91 \%$ of the island's public school students. ${ }^{8}$ Although Puerto Rico awarded 75 schools with CSRD grants in 1999 (compared with Maine's initial 11), it is important to understand that the 1994 ESEA was a far more consequential federal policy input than the CSRD program.

Indeed, the CSRD program emerged as a tool to support the reconciliation of Puerto Rico's own 1993 educational restructuring and the 1994 ESEA. The 1993 change in Puerto Rican education law came with few new resources for professional development or other means to assist the transition to a new form of school governance, and it offered little to help schools with the task of aligning their work with Puerto Rico's newly articulated education standards. Thus, when CSRD applications were first solicited in Puerto Rico in 1998 , the more than $\$ 50,000$ per year made available was welcome at schools that lacked many other obvious means for obtaining additional resources. The CSRD program meant there were chances to accelerate the enactment of already drafted school improvement plans, to plug gaps in existing implementation, and to continue the work of aligning with standards and island-wide educational priorities.

For prospective CSRD schools, the 1993 change in Puerto Rico's education law and the requirements (for most) of preparing Title I Schoolwide comprehensive plans also meant that big, abstract ideas about whole-school change had been discussed for several years and that by the time the CSRD program had been initiated, specific implementation challenges were more often a priority than overarching change visions. In other words, the CSRD program came 
on the scene when few schools were pondering broad changes, but many were considering how to carry out specific pieces of reform. Moreover, a scarcity of available substitute teachers and related logistic impediments meant many school directors were reluctant to pursue models that required substantial professional development that kept teachers from their classrooms.

The school directors were also keen to implement the PRDOE's (1998) reform plan, launched by its secretary, that identified the integration of technology across the curriculum and the "development of a bilingual citizen" as policy priorities. The technology policy prioritized access to computers and the development of computer literacy starting at the elementary school level, while the bilingual citizen initiative overtly aimed to change from the previous practice of promoting learning English as a second language to "learning English as an additional language" (p. 34). To accomplish this, English language instruction was to be integrated into the science and math curricula, computers were to "be an integral part of [English] curricular practices" (p. 34), and teachers' development of English proficiency was to be promoted through professional development.

When the CSRD program came to Puerto Rico, the island was fertile ground for the dissemination of new resources, but it was not ripe for a CSRDinitiated wave of whole-school reform. Instead, the more targeted priorities of technology integration and developing capacity for English language instruction had greater immediate currency, while math and science development also remained on the radar screen. To the extent that whole-school reform was popular in Puerto Rico, the role of the CSRD program was to enable such reform's continuation and consolidation, not its initiation.

\section{Adapting the CSRD Program in Puerto Rico}

Three key adaptations mark the PRDOE's response to the CSRD program: (a) the insistence on finding island-originating school reform models that could be available to CSRD-funded schools, (b) the solicitation and screening of the 17 comprehensive school reform models named in the Obey-Porter legislation to see if they should be made available to Puerto Rico's CSRD applicant schools, and (c) the welcoming of decidedly noncomprehensive models that responded to the commissioner's educational priorities and that could be incorporated into a Title I Schoolwide plan. The first two of these were incorporated into the PRDOE's response to the CSRD program from the very beginning. The third, which ultimately supported the broad implementation of Lightspan, Computer Curriculum Consultants, and even the Puerto Rico Science Systemic Initiative (PRSSI) as CSRD models, came later, after the PR- 
DOE's first plan for CSRD implementation had been turned down by the U.S. Department of Education.

In the winter of 1998, PRDOE officials and our colleagues began discussing CSRD implementation in Puerto Rico. In February, PRDOE officials attended a meeting of state Title I coordinators hosted by our colleagues. Two ideas emerge clearly in the notes from that February meeting: that the PRDOE and our colleagues would collaborate to try to identify potential Puerto Ricobased CSRD model providers and to co-organize a "model fair" at which prospective CSRD schools could meet model developers and gather materials.

In preparation for the model fair, in late February, our colleagues arranged to have several student assistants conduct telephone interviews with each of the 17 external model developers named in the Obey-Porter CSRD legislation to query them about their interest and capacity to work in Puerto Rico. Sixteen of the providers were successfully contacted, but only 6 indicated interest or willingness to operate in Puerto Rico. Others claimed that the high costs of operating in Puerto Rico (which requires expensive plane tickets for mainland-based providers) and/or their lack of materials in Spanish and lack of Spanish-speaking professional developers kept them from being interested at the time.

At this stage, PRDOE staff members and our colleagues both seemed to assume that Puerto Rico would implement the CSRD program in ways closely aligned with federal guidance (i.e., importing externally developed models, particularly those named in the instigating federal legislation). The goal of making an island-based model available as an option for prospective CSRD schools was an important but single exception. This shared assumption did not address Stringfield, Datnow, Ross, and Snively's (1998) acknowledgment that none of the CSRD models widely promoted in the mainland United States were initially designed for bilingual or Spanish-language implementation, nor had their efficacy been tested for such situations. Thus, also unquestioned at this stage was the very fit of the federal CSRD template (which presumed that there were research-validated models to import) to Puerto Rico.

In March 1998, our colleagues visited Puerto Rico to continue consultative CSRD support. Their first stop was a meeting at the PRDOE's main office, where they were reminded of Puerto Rico's formal educational goal to produce bilingual citizens. They then conducted site visits to (according to the agenda) "schools with CSR-type projects involving curriculum alignment with standards and a consolidated plan." The visited schools, all selected by PRDOE staff members, were implementing Articulation Strategies, Learning Alliances, the PRSSI, Educación Global, English as a Magic Car- 
pet, and Quality Educational Services of Puerto Rico. On March 23, one of our colleagues sent a letter to a PRDOE undersecretary commenting on the fit of each.

Strongly informing the search for an appropriate island-developed model was a late February memorandum from the U.S. Department of Education's senior program manager for CSRD. That memo identified SEAs as being responsible for ensuring that only research-based comprehensive school reform programs be funded. The same memo also noted that if a model adopted by a school did not include all nine federal components of the CSRD program, then schools should specify implementation plans for the missing components.

Elements of the federal memo were reflected in a March 19 letter from one of the PRDOE's undersecretaries to our colleague. That letter, which was drafted after PRDOE staff members had reviewed the results of the previously referenced model provider telephone survey that had asked about willingness to operate in Puerto Rico, indicated that "after a careful review of the 17 comprehensive reform efforts proposed in the Obey-Porter Legislation, we have identified 5 that would be aligned with the priorities of our reform efforts." The letter requested our colleague to invite Accelerated Schools, Roots \& Wings, the Coalition of Essential Schools, Expeditionary Learning Outward Bound, and High Schools That Work to the forthcoming model fair. Each accepted the invitation, except High Schools That Work. Four island-based providers-the PRSSI, Educación Global, English as a Magic Carpet, and Quality Educational Services of Puerto Rico - also attended the fair.

The model fair was not the last word on which models applicant schools could seek CSRD funding for. In May, Learning Alliances had an intriguing and temporary resurrection as a possible CSRD model, though it was not among the models included at the model fair and though it had been negatively reviewed by our colleagues as "more of a pull-out program which does not operate on a school-wide basis" and a model that met "few of the criteria defining comprehensive school reform." A May 13 memo from an island-based colleague to a mainland-based one noted that a PRDOE director had advocated including Learning Alliances, the PRSSI, and Educación Global as choices available to CSRD applicant schools.

In June, the list of models was still in flux, as the Coalition of Essential Schools and High Schools That Work were named on an early June draft of the PRDOE's implementation plan but not on the version submitted to the federal government later in the month. The submitted version included eight models: three from the mainland (Accelerated Schools, Expeditionary Learning Outward Bound, and Roots \& Wings) and five from the island (the PRSSI, 
Educación Global, Learning Alliances, Quality Educational Services of Puerto Rico, and English as a Magic Carpet).

We do not have a copy of the feedback the PRDOE received when its first implementation plan was turned down, but text in the successful second submission to the federal government hints at how the rejection was heard and responded to:

The PRDOE application for Comprehensive School Reform Demonstration Programs, which is being resubmitted, has been revised to comply with USDE and panel review recommendations. This revision purports to truly and adequately reflect the function of the CSRD program in the systemic PRDOE Educational Reform being implemented. ${ }^{9}$

The new draft named five prospective CSRD models. Only the PRSSI remained of the island-developed ones, and Lightspan was formally added. (Lightspan was not one of the 17 models named in the original Obey-Porter legislation, but it did later appear in the Northwest Regional Educational Laboratory's catalog of comprehensive school reform models in the subcategory "Reading/ Language Arts," from which it was more recently removed.)

In 1999, when the first round of 75 CSRD schools were selected in Puerto Rico, 49 opted for Lightspan. Eight opted for a model from Computer Curriculum Consultants (which had not been mentioned in the accepted plan). Fifteen selected the PRSSI (which has a math and science emphasis), and 3 opted for Expeditionary Learning Outward Bound. Roots \& Wings and Accelerated Schools were named in the PRDOE's plan, but no schools selected them.

One explanation for the popularity of Lightspan in Puerto Rico as a CSRD model (at 49 of Puerto Rico's first 75 CSRD schools) is that Lightspan responded overtly to several of the PRDOE secretary's goals to promote English acquisition and the integration of technology. Using Sony PlayStations as vehicles of curriculum delivery, Lightspan requires and supports the semi-independent study of English, mathematics, technology, and science. The Computer Curriculum Consultants model was likely popular for similar reasons. In our experience visiting schools in 2000 and assisting the PRDOE with several CSRD-related workshops, island-based personnel from Light-span and Computer Curriculum Consultants were active in their support of schools and of SEA-based educators at the PRDOE.

During that same work in 2000, the implementation of the PRSSI as a CSRD initiative seemed to be proceeding less well (the PRSSI's development had preceded CSRD by several years, and the conversion of this math and science curriculum into a mechanism for whole-school change seemed to be a struggle). Subsequently, the conversion of the PRSSI proved so awkward that 
PRSSI promoters opted not to be available as a CSRD model when Puerto Rico selected its second cohort of CSRD schools. Nonetheless, continuing the pattern of having an island-originated model available as one option, another local model, Educación Global, was promoted as a choice for the second cohort. In the first round, Educación Global had been rejected as a possible CSRD model because it had been implemented in too few sites to adequately claim research-proven effectiveness, and it had not been externally evaluated. These arguments were apparently less salient when the prospect of supporting it was revisited and there was no longer another available island-developed model.

\section{SEAs AT THE \\ Interstices of Policy and Practice}

Four points emerge from the cases reviewed here. First, as McLaughlin (1987) and Levinson and Sutton (2001) would predict, when SEA staff members act as educational policy intermediaries, they also act as policy adapters and thereby become coauthors of the ultimate policy that becomes practice. Indeed, SEA personnel can so substantially adapt a federal policy that in cases such as those sketched here-with Maine using the CSRD program to support the creation of a network of Promising Futures (Maine Commission on Secondary Education, 1998) high schools and Puerto Rico using it mostly to support the implementation of curricular reform priorities and island-originating reforms-SEA personnel as "policy co-initiators" may be an aptly descriptive label.

Second, it seems clear that research into policy adaptation should not focus only at the school or district level but is salient at multiple tiers. It also seems clear that even as SEAs take on more roles as policy intermediaries, they will retain a great amount of policy-shaping power. Although Maine had to request a waiver for its chosen CSRD policy, and Puerto Rico had to submit its CSRD plan a second time before getting federal approval, in both cases, the CSRD program as implemented showed a substantial SEA imprint. If as scholars of policy implementation our goal is to understand what happened, then we need to consider what SEA-based policy intermediaries thought, understood, and did.

Third, we should note that when SEA-based educators were faced with an externally initiated policy, they reconciled that new policy with existing salient policies, and they understood the new policy through the lenses of the policies with which they were already involved. Thus, Maine's Rider A law and Puerto Rico's Ley Orgánico 18 del 1993 both proved relevant to CSRD implementa- 
tion in the respective jurisdictions and became part of the reconciled policy as practiced in each place. CSRD implementation enabled, accelerated, or modified change efforts already under way in both places. Commissioners' priorities for high school reform or the further incorporation of English and technology use became pieces of the CSRD program as policy and practice within the relevant jurisdictions. These adaptations do not mean that the premises of federal policy were rejected but rather that much of the policy as implemented was not of federal origin.

Finally, it seems that SEA-level policy adaptation is inevitable and consistent with constructivist theories of learning (Datnow et al., 2002). Real people with real professional and personal experiences attended meetings and read federal CSRD guidance to try to figure out what they were supposed to do. But these same individuals were not blank slates; they endeavored to understand the CSRD program in relation to other problem diagnoses and strategies that were part of both their formal job descriptions and their senses of what should be. For them, new policy was like unacquired knowledge, and when they tried to make sense of that unacquired knowledge, they drew on their existing knowledge bases regarding what worked and what mattered, hence the emergence of the school portfolio and leadership team ideas in Maine and also the perseverance in Puerto Rico to identify an island-developed model.

The institutional norms of the respective SEAs, particularly norms regarding the roles of SEAs, influenced how the CSRD program was interpreted. The SEA-based policy intermediaries presumed the power or right of SEAs to mediate what schools were charged with or encouraged to do. In the act of converting the "unacquired knowledge" into "acquired knowledge," statedrafted priorities were inserted, and the knowledge (or policy) in question was transformed, becoming endowed with the problem diagnoses and strategies that were already salient to SEA officials. In Maine, when the CSRD program became the vehicle for the systemic promotion of Promising Futures (Maine Commission on Secondary Education, 1998), it became something different from what the federal legislators who first crafted the CSRD program had envisioned. To the Maine educators, the CSRD program took on more familiar dimensions and was easier to subscribe to. Similarly, in Puerto Rico, where the idea that the CSRD program would initiate comprehensive reform was viewed dubiously (as evidenced by the low number of schools that opted for wholeschool reform models compared wit models that offered more targeted assistance), the adapted idea that the CSRD program could support the consolidation and continuation of change processes initiated by the 1994 ESEA, the conversion to site-based management, and the secretary's articulation of various priorities, made the CSRD program welcome. Our findings concur with 
Spillane et al.'s (2002) that sense making is an intrinsic part of converting policy to practice.

Although policy adaptation is inevitable, it is not, in specificity, predictable. Those at the federal end have incomplete knowledge (just like everyone else in the policy-to-practice continuum). They cannot fully know how the problem diagnoses they are articulating and the strategies they are promoting will be understood and acted on beyond knowing that they will be adapted in ways reflecting local and regional mores, expectations, and priorities. Those acting at the SEA level are acting on incomplete knowledge too, incomplete knowledge of both what precipitated the federal policy and of how the mediated versions they pass on to schools will be understood and acted on there. The ideas introduced before-interpretation, negotiation, sense making, bargaining, managing ambiguity, and exercising discretion-apply.

So, what kind of SEA-level adaptations are appropriate, and how can those appropriate adaptations be encouraged? Two important answers are that we do not know and we cannot know, at least not definitively. There is little documentation of what SEA-level best practice looks like that offers any guidance about what SEA personnel should do, say, not say, and so on. Worse, the very question of what constitutes best practice at the SEA level gets muddied by the issue of best practice in relation to which policy and which setting. Yet we do know that policies that are subscribed to are implemented better and with more confidence than those that are merely complied with (Coburn, 2003); we know that such subscription emerges out of a process of sense making and reconciliation; and we know that to ensure both coherence in the implemented policy and alignment among the implementers, that sense making and reconciliation should occur explicitly and publicly (i.e., through communication about both task and premise).

As our case studies highlight, multiple policies (as well as belief systems, interpretations, and institutional mores) are simultaneously in play in ways that cannot be definitively identified and productively disaggregated. The research literature does not and apparently cannot offer sufficient clarity about best practice prescriptions federal educational policy makers might make to SEA personnel.

However, this is less of a problem than it might appear to some. The case studies both include comforting evidence of both the professionalism and empiricism of the SEA personnel we studied. Maine noted that more of its students at the high school level were struggling than at other grade levels, so it targeted resources at the problem. Similarly, Puerto Rico noted that it needed to play catch-up in promoting technological literacy—as recently as June 1994, there was only one computer available for every 328.3 students across Puerto 
Rico (Puerto Rico Department of Education, 1998, p. 7) —and that it needed more English-language instructional capacity than it currently had. So, Maine and Puerto Rico both redirected CSRD resources in ways responsive to local conditions. Moreover, SEA personnel in both locations adapted policy in ways that made it more palatable to school-based educators. Personnel at the CISE in Maine structured CSRD implementation to move away from an appearance of mandates and to build on practitioners' enthusiasm for the lateral exchange of information. Personnel in Puerto Rico recognized that promoting the CSRD program as an opportunity for whole-school change would appear ignorant of the fact that site-based management and Title I Schoolwide schools had most of the applicant schools already operating in this framework. However, making resources available that would enable the consolidation of plans for improvement that were already under way was welcome.

Federal policy makers should note that because of their familiarity with regional mores, reform histories, and current priorities, SEA-based personnel are positioned to adapt policy messages to improve local intelligibility and persuasiveness. As McLaughlin (1987) explained,

Local response may provide what reformers need, not what they want. . . Externally induced practices inconsistent with local routines, traditions, or resources are likely to be rejected in time, despite early apparent "compliance." "Muddling through" then can be seen not only as an adaptive response to demands for change but also as the more beneficial response in the long term. (p. 175)

In relation to federal policy, SEA staff members are more "local." That is, they are more proximate to state-level policy currents as well as to the cultural norms and understandings that influence response to policy. As described here, SEA staff members inevitably adapt federal initiatives and that adaptation may be a key component of a policy's ultimate viability.

Federal policy makers should also note how SEA-level adaptations can mobilize additional resources and even make systemic, enduring improvements more probable. Since 1998, 33 of Maine's 140 high schools have been induced to engage with Promising Futures (Maine Commission on Secondary Education, 1998) through the CSRD program, and several dozen others have at least attempted to reconcile their school change plans with that document in unsuccessful CSRD bids. Moreover, the CSRD-aided implementation of Promising Futures has drawn the interest of the Gates Foundation, which through Maine's Mitchell Institute gave the state $\$ 10$ million for Promising Futures implementation at more high schools. The status quo that led to Maine's relative struggles at the secondary level continues to be challenged, with adapted federal policy contributing substantively to that challenge. 


\section{Notes}

1. When the No Child Left Behind Act of 2001 was passed in January 2002, the federal CSRD program was renamed the Comprehensive School Reform program. To emphasize the historical context of the research presented here, we use the older name.

2. The commission was deeply concerned with ensuring the input of students, parents, and other local stakeholders, so focus groups across the state were convened to solicit ideas from each of these groups.

3. Ted Sizer founded the Coalition of Essential Schools in 1984; he and his wife Nancy live in Massachusetts.

4. CSRD funds were allocated largely according to the number of enrolled low-income students in a state, so states with small enrollments qualified for less funding. For SEAs, these small sums were further restricted by a formulaic federal policy requiring that no more than $5 \%$ of states' allocations be reserved at the state level (instead of disseminated to schools).

5. Very few secondary schools in Maine are Title I schools, so this waiver was necessary if the CSRD program in Maine was to be targeted at high schools.

6. See Fisher (2003) for a lengthy depiction of this school's efforts, intentions, and accomplishments in the 1990s.

7. As a downside of the requisite blending of federal CSRD policies and state Rider A procurement policies, Rider A contracts demanded specificity only for how the annual \$50,000 CSRD allocations were spent. Thus, although CISE personnel overseeing CSRD implementation were interested in learning how the CSRD program was integrated with other school efforts, and although federal nonregulatory CSRD guidance expected the combination of CSRD funds with other monies, the state's detailed and multifaceted reporting protocol (the portfolio) and its legal rationale (Rider A) were directly concerned only with the discrete modest expenditure.

8. The Title I Schoolwide figures come from the U.S. Department of Education. The 1996 and 1999 figures come from an archived report titled State Education Indicators With a Focus on Title I (U.S. Department of Education, Office of the Under Secretary, Planning and Evaluation Service, 2001), and the 2001 figures come from Overview of Public Elementary and Secondary Schools and Districts: School Year 2001-02 (National Center for Education Statistics, 2003, Table 9). Intriguingly, in a report prepared by Nitza Pérez of the PRDOE in January 1998, the tallied number of Title I Schoolwide schools in Puerto Rico had climbed from 159 in 1995-1996 to 272 in 19961997 and 463 in 1997-1998. These figures were shared at the April 1998 CSRD model provider showcase in San Juan. It is unclear why they do not exactly match up with the figures of the National Center for Education Statistics.

9. The systemic PRDOE reform that was mentioned referenced a revised plan produced by the PRDOE in March 1998 under the auspices of then secretary Victor Fajardo (Puerto Rico Department of Education, 1998).

\section{REFERENCES}

Anstrom, K. (1995). New directions for Chapter 1/Title I. Directions in Language and Education, 1(7), 1-7.

Bakhtin, M. (1993). Toward a philosophy of the act (V. Liapunov, Trans., V. Liapunov \& M. Holquist, Eds.). Austin: University of Texas Press.

Berends, M., Bodilly, S., \& Kirby, S. N. (2002). Looking back over a decade of wholeschool reform: The experience of New American Schools. Phi Delta Kappan, 84(2), $168-175$. 
Berends, M., Kirby, S. N., Naftel, S., \& McKelvey, C. J. (2001). Implementation and performance in New American Schools: Three years into scale-up. Santa Monica, CA: RAND.

Borman, G., Hewes, G., Overman, L., \& Brown, S. (2003). Comprehensive school reform and achievement: A meta-analysis. Review of Educational Research, 73(2), 125-230.

Coady, M., Hamann, E., Harrington, M., Pacheco, M., Pho, S., \& Yedin, J. (2003). Claiming opportunities: A handbook for improving education for English Language Learners through comprehensive school reform. Providence, RI: Education Alliance at Brown University.

Coburn, C. (2001). Collective sense-making about reading: How teachers mediate reading policy in their professional communities. Educational Evaluation and Policy Analysis, 23(2), 145-170.

Coburn, C. (2003). Rethinking scale: Moving beyond numbers to deep and lasting change. Educational Researcher, 32(6), 3-12.

Cresswell, J. (1998). Qualitative inquiry and research design. Thousand Oaks, CA: Sage.

Cuban, L. (1998). How schools change reforms: Redefining reform success and failure. Teachers College Record, 99(3), 453-477.

Datnow, A., Hubbard, L., \& Mehan, H. (2002). Extending education reform: From one school to many. London: RoutledgeFarmer.

Desimone, L. (2002). How can comprehensive school reform models be successfully implemented? Review of Educational Research, 72(3), 433-479.

Eisenhart, M. A. (2001). Changing conceptions of culture and ethnographic methodology: Recent thematic shifts and their implications for research on teaching. In V. Richardson (Ed.), The handbook of research on teaching (4th ed., pp. 209-225).Washington, DC: American Educational Research Association.

Eisenhart, M. A., \& Howe, K. R. (1992). Validity in educational research. In M. LeCompte, W. Millroy, \& J. Preissle (Eds.), The handbook of qualitative research in education (pp. 643680). San Diego, CA: Academic Press.

Elmore, R. F. (1980). Backward mapping: Implementation research and policy decision. Political Science Quarterly, 94(4), 601-609.

Fisher, P. (2003). Democracy and equity in the classroom. In J. DiMartino, J. Clarke, \& D. Wolk (Eds.), Personalized learning: Preparing high school students to create their futures (pp. 103118). Lanham, MD: Scarecrow.

Gigerenzer, G., \& Selton, R. (2001). Rethinking rationality. In G. Gigerenzer \& R. Selton (Eds.), Bounded rationality: The adaptive toolbox (pp. 1-12). Cambridge, MA: MIT Press.

Goggin, M. L., Bowman, A., Lester, J., \& O’Toole, L. (1990). Implementation theory and practice: Toward a third generation. New York: HarperCollins.

Hamann, E. (2003). The educational welcome of Latinos in the New South. Westport, CT: Praeger.

Hamann, E., \& Lane, B. (2002, April). “We're from the state and we're here to help”: State-level innovations in support of high school improvement. Paper presented the annual meeting of the American Educational Research Association, New Orleans, LA.

Hamann, E., Lane, B., \& Hudak, M. (2001). CSRD roll-out in Maine: Lessons from a statewide case study (rev. Web ed.). Providence, RI: Northeast and Islands Regional Educational Laboratory at Brown University. 
Hamann, E., Lane, B., \& Johnson, S. (2001, April). School portfolios, critical collegiality, and comprehensive school reform. Paper presented at the annual meeting of the American Educational Research Association, Seattle, WA.

Hamann, E., Lane, B., Smith, P., \& Piñeiro, O. (2001). Lessons and possibilities: Notes regarding CSRD in Puerto Rico (rev. Web ed.). Providence, RI: Northeast and Islands Regional Educational Laboratory at Brown University.

Hicks, D. (1999, April). Self and other in Bakhtin's early philosophical essays: Prelude to a theory of prose consciousness. Paper presented at the annual meeting of the American Educational Research Association, Montreal, Canada.

Hill, H. C. (2001). Policy is not enough: Language and the interpretation of state standards. American Educational Research Journal, 38(2), 289-318.

Honig, M. I. (2001, April). Managing from the middle: The role of intermediary organizations in the implementation of complex education policy. Paper presented at the annual meeting of the American Educational Research Association, Seattle, WA.

Irvine, P. D., \& Larson, J. (2001). Literacy packages in practice: Constructing academic disadvantage. In J. Larson (Ed.), Literacy as snake oil: Beyond the quick fix (pp. 4570). New York: Peter Lang.

Johnson, F. (2001). Revenues and expenditures for public elementary and secondary education: School year 1998-99 (NCES 2001-321). Education Statistics Quarterly: Elementary and Secondary Education. Retrieved from http://nces.ed.gov/pubs2002/quarterly/fall/q3-6.asp

Lane, B., \& Hamann, E. (2000). Maine Comprehensive School Reform Demonstration program: Year one evaluation report. Providence, RI: Northeast and Islands Regional Educational Laboratory at Brown University.

Lane, B., \& Hamann, E. (2001). Maine Comprehensive School Reform Demonstration program: Year two evaluation report. Providence, RI: The Education Alliance at Brown University.

Lane, B., \& Hamann, E. (2002a). Maine Comprehensive School Reform Demonstration program: Cohort I-Year three evaluation report. Providence, RI: The Education Alliance at Brown University.

Lane, B., \& Hamann, E. (2002b). Maine Comprehensive School Reform Demonstration program: Cohort II-Year one evaluation report. Providence, RI: The Education Alliance at Brown University.

Leedom, D. (2001). Final report: Sense-making symposium. Vienna, VA: Command and Control Research Program, Office of the Assistant Secretary of Defense for Command, Control, Communications, and Intelligence.

Levinson, B., \& Sutton M. (2001). Introduction: Policy as/in practice-A sociocultural approach to the study of educational policy. In M. Sutton \& B. Levinson (Eds.), Policy as practice: Toward a comparative sociocultural analysis of educational policy (pp. 122). Westport, CT: Ablex.

Lusi, S. F. (1997). The role of state departments of education in complex school reform. New York: Teachers College Press.

Lytle, J. (2002). Whole-school reform from the inside. Phi Delta Kappan, 84(2), 164-167.

Maine Commission on Secondary Education. (1998). Promising Futures: A call to improve learning for Maine's secondary students. Augusta: Maine Department of Education. 
McLaughlin, M. W. (1987). Learning from experience: Lessons from policy implementation. Educational Evaluation and Policy Analysis, 9, 171-178.

McQuillan, P. (1998). Educational opportunity in an urban American high school: A cultural analysis. Albany: State University of New York Press.

Murphy, J., \& Datnow, A. (2003). Leadership lessons from comprehensive school reforms. Thousand Oaks, CA: Corwin Press.

Nader, L. (1972). Up the anthropologist-Perspectives gained from studying up. In D. Hymes (Ed.), Reinventing anthropology (pp. 284-311). New York: Pantheon.

National Center for Education Statistics. (2003, May). Overview of public elementary and secondary schools and districts: School year 2001-02. Retrieved August 28, 2003, from http:// nces.ed.gov/pubs2003/overview03/

Nieto, S. (2000). Puerto Rican students in U.S. Schools: A brief history. In S. Nieto (Ed.), Puerto Rican students in U.S. schools (pp. 5-37). Mahwah, NJ: Lawrence Erlbaum.

No Child Left Behind Act, 20 U.S.C. § 6301 et seq. (2002).

Ozga, J. (1999). Policy research in educational settings: Contested terrain. Buckingham, UK: Open University Press.

Patton, M. Q. (1990). Qualitative evaluation and research methods (2nd ed.). Newbury Park, CA: Sage.

Puerto Rico Department of Education. (1998). Education reform in Puerto Rico. San Juan: Author.

Quality counts 2000: Who should teach? (2000, January 13). Education Week, 19.

Resnick, M. C. (1993). ESL and language planning in Puerto Rican education. TESOL Quarterly, 27(2), 259-273.

Ruff, D., Smith, D., \& Miller, L. (2000). The view from Maine: Developing learner-centered accountability in a local control state. In B. L. Whitford \& K. Jones (Eds.), Accountability, assessment, and teacher commitment: Lessons from Kentucky's reform efforts (pp. 163-178). Albany: State University of New York Press.

Rust, F., \& Freidus, H. (Eds.). (2001). Guiding school change: The role and work of change agents. New York: Teachers College Press.

Sack, J. L. (2002, January 30). Experts debate effect of whole-school reform. Education Week, 21, 6 .

Shore, C., \& Wright, S. (1997). Policy: A new field of anthropology. In C. Shore \& S. Wright (Eds.), Anthropology of policy: Critical perspectives on governance and power (pp. 3-39). London: Routledge.

Spillane, J. (1998). State policy and the non-monolithic nature of the local school district: Organization and professional practice considerations. American Educational Research Journal, 35(1), 33-63.

Spillane, J., Reiser, B., \& Reimer, T. (2002). Policy implementation and cognition: Reframing and refocusing policy implementation research. Review of Educational Research, $72(3), 387-431$.

Stake, R. (1995). The art of case study research. Thousand Oaks, CA: Sage.

Stringfield, S., Datnow, A., Ross, S. M., \& Snively, F. (1998). Scaling up school restructuring in multicultural, multilingual contexts: Early observations from Sunland County. Education and Urban Society, 30(3), 326-357.

Stringfield, S., Millsap, M. A., \& Herman, R. (1997). Urban and suburban/rural special 
strategies for educating disadvantaged children: Findings and policy implications of a longitudinal study. Retrieved August 28, 2003, from http://www.csos.jhu.edu/Otherlinks/SpecialStrategies/title.htm

Sutton, M., \& Levinson, B. (Eds.). (2001). Policy as practice: Toward a comparative sociocultural analysis of educational policy. Westport, CT: Ablex.

U.S. Department of Education, Office of Elementary and Secondary Education. (1998). Archived information: FY 1998 allocations. Retrieved January 7, 2004, from http://www.ed.gov/offices/OESE/archives/compreform/table98.html

U.S. Department of Education, Office of the Under Secretary, Planning and Evaluation Service. (2001). State education indicators with a focus on Title I. Retrieved August 28, 2003, from http://www.ed.gov/offices/OUS/PES/esed/2000 indicators/

Viadero, D. (2001, November 7). Whole-school projects show mixed results. Education Week, 21, 24-25.

Weick, K. E. (1995). Sense-making in organizations. Thousand Oaks, CA: Sage.

Whitehurst, G. (2003, April). The Institute of Educational Sciences: New wine in new bottles. Invited address presented at the annual meeting of the American Educational Research Association, Chicago.

Young, M. (1999). Multifocal educational policy research: Toward a method for enhancing traditional educational policy studies. American Educational Research Journal, 36, $677-714$.

Dr. Edmund "Ted" Hamann is a research and evaluation specialist at The Education Alliance at Brown University, where he studies and supports the implementation of comprehensive school reform at the high school level, examines the inclusion and exclusion of English-language learners from academic programs, and studies how educational policy is changed by its conversion into practice. He is the author of The Educational Welcome of Latinos in the New South (Praeger, 2003), a coauthor (with Maria Coady, Margaret Harrington, Maria Pacheco, Samboeun Pho, and Jane Yedlin) of Claiming Opportunities: A Handbook for Improving Education for English Language Learners Through Comprehensive School Reform (The Education Alliance at Brown University, 2003), and a coeditor (with Stanton Wortham and Enrique G. Murillo, Jr.) of Education in the New Latino Diaspora: Policy and the Politics of Identity (Ablex, 2001).

Brett Lane is a research and evaluation specialist at The Education Alliance at Brown University and was formerly at the Northwest Regional Educational Laboratory. He has worked extensively with state departments of education in the Northeast supporting their implementations of federal programs, notably the Comprehensive School Reform program. He has also developed technical assistance materials supporting the launching of charter schools. 